\title{
A PEDAGOGIA DOS MULTILETRAMENTOS: UMA PROPOSTA PARA A FORMAÇÃO CONTINUADA DE PROFESSORES
}

\author{
Marcia Juliana Dias de Aguiar * \\ Adriana Fischer **
}

\begin{abstract}
Resumo: O objetivo deste artigo é apresentar um estudo bibliográfico a respeito da Pedagogia do Multiletramentos (New London Group, 1996), exemplificando seus conceitos de maneira aplicada, a fim de oportunizar sugestões para o aprimoramento das atividades docentes, considerando os sentidos dos textos multimodais e semióticos. Pretende-se também promover a reflexão sobre a importância do processo de formação continuada (Freire, 2011; Ghedin, 2005) como uma maneira eficaz de se entrar em contato com novas formas de pensar o processo de ensinar e aprender em sala de aula. Com isso,o professor buscará complementar seu agir docente, analisando-o crítica e reflexivamente, bem como testando novos métodos e abordagens de ensino, contemplando os textos multimodais de nossa contemporaneidade. Neste contexto, a Pedagogia dos Multiletramentos poderá ser estudada e analisada pelos professores, servindo como suporte teórico para a elaboração de atividades significativas de leitura e escrita em sala de aula.
\end{abstract}

Palavras-chave: Multiletramentos. Análise Crítica do Discurso. Formação Continuada de Professores.

\begin{abstract}
The aim of this article is to present a bibliographic study about the Pedagogy of Multiliteracies (New London Group, 1996), exemplifying its concepts in a practical way, in order to suggest ways to improve the teachers' practice, considering the meanings of multimodal and semiotic texts. It is also intended to emphasize the importance of the teacher continued formation (Freire, 2011; Ghedin, 2005) as a significant way to be in touch with new manners of thinking their practices in the classroom. With this in mind, teachers will look for and test new methods through the critical and reflexive analysis of his/her practices, which improve the teaching and learning process, approaching the semiotic and multimodal discourses of our contemporary time. In this context, the Pedagogy of Multiliteracies can be studied and analyzed by teachers, serving as a theoretical support to the elaboration as significative reading and writing activities in classroom.
\end{abstract}

Keywords: Multiliteracies. Critical Discourse Analysis. Teachers' Continued Education.

\footnotetext{
* Mestre em Estudos Linguísticos (UFSM); Especialista em Gestão Educacional (UFSM). Contato: amysunbr@yahoo.com.br

** Doutora em Linguística Aplicada (UFSC), professora da Pós-Graduação em Letras da Universidade Católica de Pelotas e do Centro de Ciências da Educação da Universidade Regional de Blumenau. Contato: afischerpirotta@gmail.com
} 


\section{Introdução}

Muitos avanços são observados atualmente no âmbito da educação em termos de métodos e técnicas voltados às atividades de leitura e escrita. Porém, como as atividades de leitura e escrita estão sendo realizadas sob a ótica da teoria dos Multiletramentos? Como está a conscientização dos professores em relação à formação continuada? Como visualizar a teoria da Pedagogia dos Multiletramentos de maneira mais prática?

Esses questionamentos norteiam a pesquisa bibliográfica apresentada neste artigo. O estudo da Pedagogia dos Multiletramentos como forma de se oportunizar práticas letradas mais significativas em sala de aula é o tópico deste estudo. O objetivo é instigar professores em formação continuada a buscar entender melhor tal Pedagogia, a fim de implementar as atividades de leitura e escrita de textos multimodais. É importante ressaltar que o entendimento apresentado neste texto não se constitui em verdade absoluta a respeito da teoria, mas uma interpretação do que se pode fazer, pensar sobre o assunto. Mais estudos, mais pesquisas, mais testes com as atividades precisam ser elaborados. No entanto, tudo isso só começa com a reflexão e interesse dos professores em formação continuada pelo assunto.

Sabemos que o acesso ao conhecimento ao longo dos últimos anos tem acontecido de forma mais rápida e mais ampla em função do advento da globalização com suporte fundamental das tecnologias da informação e comunicação (TIC). Nesse contexto, o processo de formação de professores foi influenciado diferentemente ao longo dos anos. Metodologias, estratégias de ensinar foram concebidas de modo diverso em uma perspectiva diacrônica.

Da mesma maneira, o contexto de sala de aula é influenciado pelas crenças de seus professores que, na maioria das vezes, são configuradas por uma somatória das experiências desse professor ao longo dos anos. Além disso, as crenças podem estar associadas ao conhecimento adquirido em seu processo de formação e formação continuada, mais o conhecimento adquirido pela experiência e prática diária em sala de aula (GIMENEZ, 1994).

Gimenez (1994), ao postular sobre as crenças de professores, aponta que 
os professores continuamente constroem, elaboram e testam sua teoria pessoal do mundo (CLARK, 1986) Neste paradigma o modo como professores percebem o trabalho deles e as conexões que eles fazem entre as experiências e o conhecimento desempenha um importante papel para entender o seu trabalho. (GIMENEZ,1994, p.13)

Com isso, é necessário que os professores revejam, questionem suas crenças sobre o ensinar através de um processo de análise crítica do que realmente acontece em sala de aula, bem como dos efeitos produzidos no processo de ensino e aprendizagem. Gimenez (1994) relata que devemos analisar o conjunto de crenças que norteiam a prática do professor e também as fontes potenciais dessas crenças, a fim de que aquelas crenças que não contribuem para o melhoramento do processo de ensino e aprendizagem sejam renovadas e melhoradas com o passar do tempo.

Burns (1999) teoriza sobre a abordagem de pesquisa-ação como instrumento para melhoramentos no ambiente de sala de aula, bem como aperfeiçoamento do professor. Podemos inferir que para a formação continuada de um professor, são necessários, além do uso de novos conjuntos teóricos, uma abordagem de pesquisa-ação que o oriente e organize o seu pensar e agir na busca do aprimoramento.

Para essa mesma autora, os professores devem ter ciência de que

a indagação sobre a sala de aula e a autorreflexão são componentes importantes para o crescimento profissional, fornecendo uma fonte profunda para planejamento pedagógico e ação, capacitando-os para estruturar as decisões locais da sala de aula dentro de considerações educacionais, institucionais e teóricas mais amplas. (BURNS,1999, p.16)

O professor deve ser incentivado a rever suas práticas de sala de aula, principalmente, pois vive em uma sociedade em que as atividades semióticas e multimodais são cada vez mais presentes. Neste contexto, temos como atividade multimodal a definição dada por Jewitt:

A multimodalidade como os multiletramentos têm surgido em resposta a mudança na paisagem social e semiótica. Chave para as perspectivas multimodais sobre o letramento é a suposição básica que os significados são produzidos (bem como distribuídos, interpretados, e refeitos) através 
de muitos recursos representacionais e comunicacionais, do qual a língua é apenas uma. (...) A multimodalidade atende ao significado como é feito através das configurações situadas através da imagem, gestos, o olhar, postura corporal, som, escrita, música, fala e assim por diante. (JEWITT, 2008, p. 246)

Com isso, uma nova configuração se apresenta nos ambientes de trabalho, uma caracterização diferenciada da vida pública e privada dos sujeitos se faz presente de forma bastante intensa. Nesse sentido, desprezar essa realidade em sala de aula e não analisá-la criticamente pode, de certa forma, despreparar os nossos alunos na atuação em sociedade futuramente, no pleno exercício de sua cidadania, atuação significativa no mercado de trabalho e na vida pública em práticas multiletradas contemporâneas.

Sendo assim, o objetivo deste artigo é apresentar uma revisão bibliográfica sobre a pedagogia dos multiletramentos (New London Group, 1996) como uma proposta para complementar as práticas docentes, tendo em vista a relevância das TICs ${ }^{1}$ e da multimodalidade na nossa sociedade atual. Além disso, apresentaremos sumariamente alguns aspectos da Análise Crítica do Discurso de Fairclough como parte importante dentro da pedagogia, buscando ler e escrever dentro dessas práticas multiletradas, de forma mais reflexiva, legítima, desvelando sentidos, resistindo e alterando o status quo. Acreditamos que o estudo da Análise Crítica do Discurso possa contribuir, principalmente, com um dos componentes propostos da Pedagogia que é o enquadramento crítico (critical framing). Por fim, objetivamos também instigar um processo de reflexão que destaque a importância da formação continuada para o aprimoramento profissional de professores de língua materna e língua estrangeira também.

\section{A Pedagogia dos Multiletramentos}

A pedagogia dos multiletramentos surgiu em 1996 quando o New London Group (NLG,1996), reunido para discutir o estado da pedagogia dos letramentos, em função das disparidades nos resultados educacionais que pareciam não estar melhorando nos Estados Unidos, Austrália e Reino Unido, resolveu discutir questões como:

1 TICs: Tecnologias da Informação e Comunicação 
as áreas principais de preocupação comum ou complementar incluiam a tensão pedagógica entre a imersão e os modelos explícitos de ensino; o desafio da diversidade cultural e linguística; os novos e proeminentes modos das tecnologias da informação; e as mudanças no uso dos textos nos ambientes de trabalho reestruturados. (NLG, 1996, p. 62)

Deste modo, o NLG com suas discussões e teorizações construiu uma pedagogia a ser aplicada, experimentada e validada em sala de aula pelos professores como forma de qualificar as práticas docentes na escola. Cope e Kalantziz (2001), ao elaborarem os princípios Prática Situada, Instrução Explícita, Estrutura Crítica e a Prática Transformada, apontam que tal sequência não é para ser concebida de forma rígida nem para sugerir que o que os professores estão fazendo até o momento é inadequado. Os autores sustentam que a pedagogia dos multiletramentos é mais um recurso didático disponível aos professores para complementar suas práticas em sala de aula.

Nos estudos sobre os Multiletramentos, encontramos dicotomias que podem colaborar para entendermos e refletirmos sobre os contextos de ensino. Neste caso, pretendemos destacar a importância das atividades no âmbito do letramento escolar. Ou seja, concordamos com a ideia de Bunzen (2010) sobre as dicotomias do letramento versus escolarização, e do letramento social versus letramento escolar, que em suas bases, originam-se das concepções do modelo ideológico e autônomo de Brian Street (2003). Bunzen ressalta que:

O termo letramento escolar não deveria a priori ser utilizado como algo necessariamente negativo ou perverso, autônomo e estático por natureza, mas como um conjunto de práticas discursivas da esfera escolar que envolvem os usos da escrita em contínua inter-relação com outras linguagens. (BUNZEN, 2010, p. 100)

Em outros termos, concebemos as práticas letradas escolares como autênticas e legítimas dentro dessa perspectiva. Elas são constituídas, organizadas por seus gêneros textuais típicos do contexto escolar, devendo ser valorizadas e aprimoradas. Com isso, sustentamos que a suplementação e o aprimoramento da prática docente é de extrema importância para a evolução do processo de escolarização. 
Jewitt (2008) alega que nossa sociedade contemporânea apresenta como características significativas a globalização, a fluidez, as redes de informação, o capitalismo rápido, a multimodalidade, entre outros aspectos. E essas questões certamente devem ser consideradas no ambiente de sala de aula. Por sua vez, é interessante também pensar a globalização, o neoliberalismo sob uma ótica crítica através desta pedagogia. Edna Castro de Oliveira no prefácio do livro "Pedagogia da Autonomia" de Paulo Freire argumenta que:

Neste contexto em que o ideário neoliberal incorpora, entre outras, a categoria da autonomia, é preciso também atentar para a força de seu discurso ideológico e para as inversões que pode operar no pensamento e na prática pedagógica ao estimular o individualismo e a competitividade. Como contraponto, denunciando o mal-estar que vem sendo produzido pela ética do mercado, Freire anuncia a solidariedade enquanto compromisso histórico de homens e mulheres como uma das formas de lutas capazes de promover e instaurar a 'ética universal do ser humano. (FREIRE, 2011, p. 13)

De acordo com Oliveira (2011), devemos considerar a realidade contemporânea em sala de aula em uma perspectiva de análise crítica, de reflexão, de desvelar o senso comum, de questionar e resistir às relações de poder, de resistência à ordem social, que afete a dignidade humana, questionar esta ética de mercado, bem como modificá-la em prol da ética e bons valores do homem.

Para Jewitt (2008, p. 242), ressaltar os textos multimodais nas práticas de sala de aula é importante fator para o enriquecimento do processo de aprendizagem do aluno, o qual traz de seu contexto fora da escola muito dessas práticas.

Segundo a autora (2008, p. 242),”o foco está na multimodalidade, nas representações e nos potenciais de aprendizagem dos materiais de ensino e os modos com os quais os professores e estudantes ativam esses textos através da sua interação em sala de aula".

Por outro lado, o NLG (1996) assinala que entender e controlar as formas representacionais, ou seja, a multimodalidade, as imagens associadas à palavra escrita exigem uma preparação diferenciada. Além disso, devemos considerar também a questão das diferenças culturais, 
a diversidade global e local, as disparidades sociais, as mudanças na vida pública e econômica, as mudanças no âmbito das TICs e os novos contextos no trabalho como modos de produção de sentido significativos para serem analisados criticamente, debatidos e experimentados pelos discentes em aula.

Com isso, o debate a respeito desta nova configuração social resultou na concepção de uma multiplicidade de atividades semióticas, que deu origem à palavra multiletramentos. Para os autores do NLG (1996, p. 63), a palavra multiletramentos representa uma "nova ordem emergente cultural, institucional e global, ou seja, a multiplicidade de canais de comunicação e mídia, e a crescente saliência da diversidade linguística e cultural".

Nesse contexto, para o exercício de uma cidadania efetiva e o trabalho produtivo em práticas multiletradas e multisemióticas serão necessários linguagens e discursos múltiplos com padrões de comunicação que mais frequentemente cruzam os limites culturais das comunidades e da nação (NLG, 1996). Em outros termos, professores e estudantes dos letramentos devem se ver como participantes na mudança social, como aprendizes, que podem ser designers, ou melhor, produtores e transformadores ativos de significados dentro de sua comunidade.

Para isso, o NLG (1996) estabelece uma proposta do que e do como a pedagogia pode ser implementada pelos professores em suas práticas docentes. O que da pedagogia estaria relacionado com a reestruturação do currículo e seus conteúdos, o como ressaltaria o modo como tais conteúdos seriam apresentados em sala de aula.

É digno de nota o pensamento de Jewitt (2008) a respeito da construção do currículo dentro de uma pedagogia dos multiletramentos:

\begin{abstract}
(...) os multiletramentos têm em seu centro a ideia de um currículo responsivo ao social e cultural. (...) Com esta pauta explícita para a mudança social, o objetivo pedagógico dos multiletramentos é atender aos textos múltiplos e multimodais e o amplo alcance das práticas de letramento que os estudantes estão engajados. (...) Desta perspectiva, os objetivos social e político dos multiletramentos são situar os professores e os estudantes como participantes ativos na mudança social, os designers ativos do futuro social. (JEWITT, 2008, p. 245)
\end{abstract}

No que diz respeito então ao que da pedagogia dos multiletramentos, o NLG (1996) salienta uma nova metalinguagem a ser pensada pelos 
professores em que o conceito de design faz-se presente e constitui uma linha de pensamento a ser seguida na seleção dos conteúdos, vistos como práticas sociais multiletradas, a serem trabalhados nas práticas de letramento escolar.

O NLG (1996) dispõe seis elementos de design que devem ser considerados no processo de produção de significado: a) o sentido linguístico, b) o sentido visual, c) o sentido auditivo, d) o sentido gestual, e) o sentido espacial e f) o sentido multimodal, o qual compreende os cinco primeiros.

Sendo assim, toda prática multiletrada e multisemiótica deve ser analisada criticamente, destacando esses seis elementos do design. A tabela a seguir contém sumariamente os conceitos principais defendidos pelo NLG (1996, p. 77) e que podem ser utilizados na seleção e análise de atividades semióticas:

Tabela 1: Conceitos derivados do design

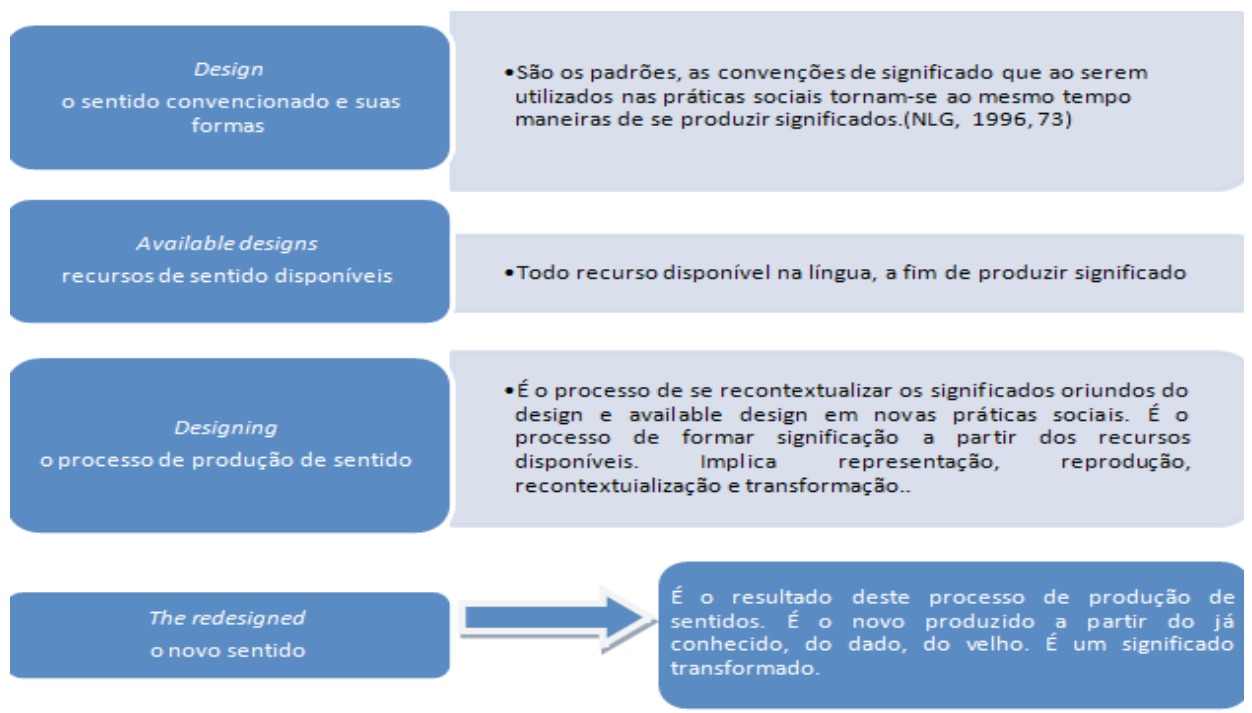

\subsection{Análise e sugestões em relação aos conceitos derivados do Design}

Como exemplo, para enfocar conceitos derivados do Design, trazemos uma das versões da obra Mona Lisa de Leonardo da Vinci. De acordo com informações obtidas no Wikipédia, tal obra foi produzida no 
ano de 1503 , o pintor representa a beleza da mulher de sua época, sendo sua musa inspiradora. Conforme historiadores, Mona Lisa era a esposa de um rico comerciante de seda e membro do governo de Florença. Pela análise dessa obra e suas versões, pretendemos aplicar os quatro conceitos em relação ao design com exemplos para melhor esclarecê-los.

Figura 1: Versões do quadro da Mona Lisa

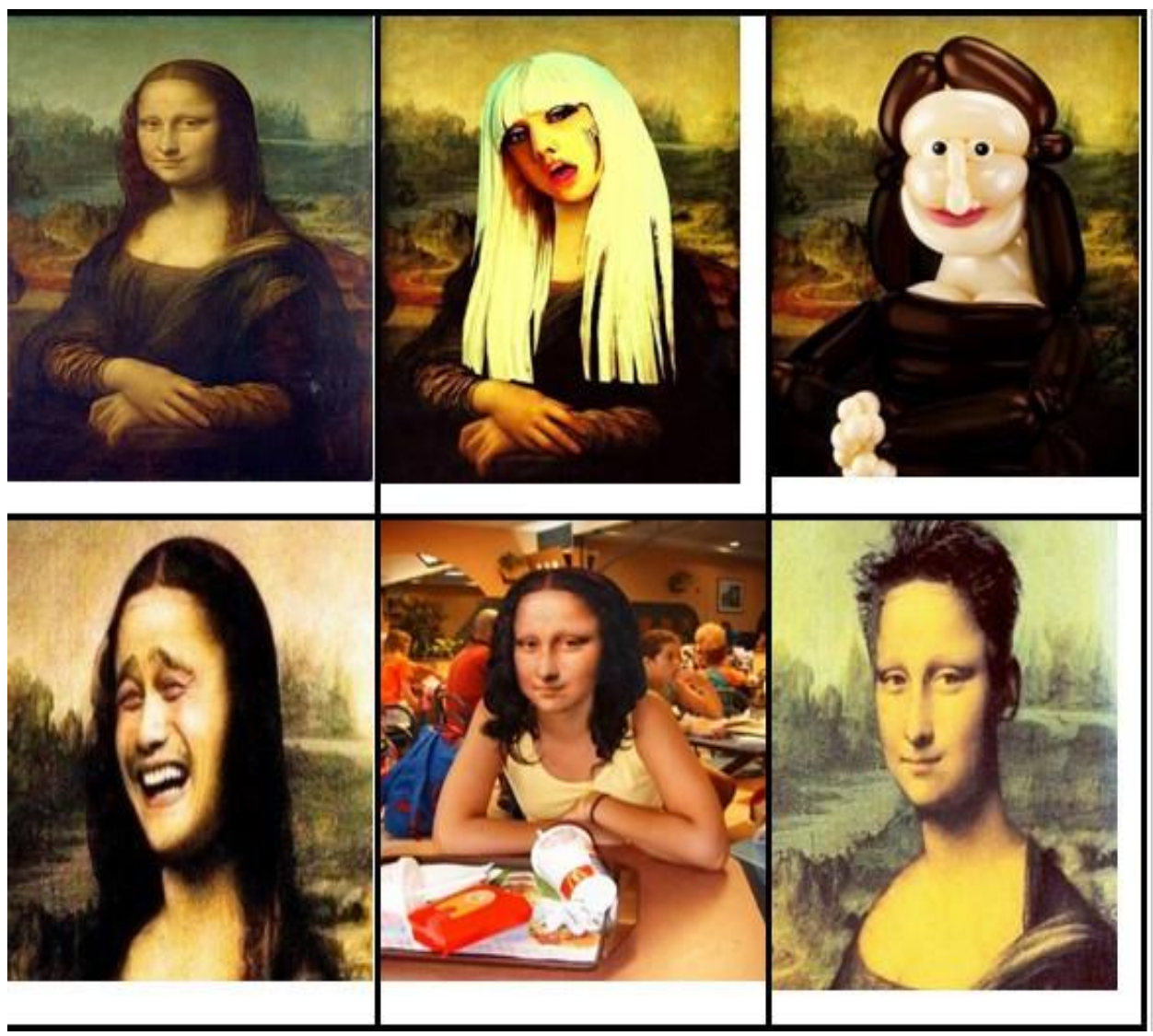

Fonte: A imagem original de Mona Lisa foi retirada de: http://pt.wikipedia.org/wiki/ Mona_Lisa e as outras versões de: http://www.ogatonerd.com.br/2012/07/

Temos na obra de Da Vinci, reproduzida há mais ou menos uns quinhentos anos, a produção de sentido e representação de um quadro em que é esboçada uma mulher. Tal quadro representa uma ideia, um sentido já dado e convencionado que chamamos de design. O quadro constitui 
uma forma, estrutura de significado existente, até os dias de hoje, como representação de um período passado de nossa história.

Ao analisarmos os outros quadros, que são reproduções, recontextualizações do quadro original de Da Vinci, percebemos que os designers-produtores de sentido- queriam transformar um velho sentido em algo novo. Para isso, eles provavelmente se utilizaram de recursos disponíveis no nosso sistema semiótico para produzir tal mudança. Podemos inferir que os available designs utilizados na construção dessas novas imagens de Mona Lisa foram: computador, algum tipo de software de edição de imagens, outras imagens de sujeitos mais atuais, balões canudos, diversas cores, as representações dos sujeitos na realidade atual, o próprio sentido materializado em uma forma de linguagem semiótica, ou seja, o próprio design torna-se um recurso de significação disponível.

O processo de elaboração desse novo produto, envolvendo essa transformação, nova representação, chamaríamos de designing. E o resultado, ou seja, essas imagens prontas teríamos o redesigned. São os novos significados e sentidos produzidos como representação de nossa contemporaneidade misturada com representações do passado.

De acordo com o NLG (1996), o produto do redesigned pode ser algo mais ou menos criativo. No caso das novas versões de Mona Lisa, produzidas a partir do quadro original. Elas são bem criativas, têm certamente a intenção de provocar o humor, bem como mostrar discursos bem presentes atualmente como o imperialismo da marca Mac Donalds, a popularidade de uma cantora como a Lady Gaga, a onda dos memes nas redes sociais com o atleta de basquete Yao Ming, e um corte de cabelo da moda. Tais questões podem ser discutidas em sala de aula e podemos mostrar para os alunos como os significados se constroem e reconstroem na nossa realidade multimodal e semiótica dentro da pedagogia dos multiletramentos.

Vale a pena ressaltar que temos instrumentos variados $\mathrm{e}$ significativos para análise de imagens, dentro de teorias da multimodalidade (cf. KRESS e VAN LEEUWEN, 1996), semiótica social (cf. HALLIDAY, 1978), a análise do discurso da mídia (cf. FAIRCLOUGH, 1995), porém nosso objetivo aqui é somente exemplificar os conceitos de design, available designs, designing, e redesigned. Além disso, tais imagens podem ser abordadas em sala de aula de diversas maneiras de acordo com os objetivos perseguidos pelos professores, porém, neste artigo, elas 
foram usadas como exemplo dos conceitos previamente apontados.

$\mathrm{Na}$ busca de um entendimento a respeito dessa metalinguagem proposta pelo NLG, em outros termos, para se entender o que da pedagogia dos multiletramentos, temos também como exemplo dois filmes. De fato, podemos pensar o filme "Espelho, espelho meu?" como uma releitura de um conto de fadas "originário da tradição oral alemã, que foi compilado pelos Irmãos Grimm e publicado entre os anos de 1812 e 1822" da Branca de Neve . Esse processo que se inicia no design e acaba no produto do redesigned pode ser constatado nesta releitura de uma obra clássica do século XIX que é reconstruída, englobando aspectos de duas histórias a da Branca de Neve propriamente dita e com nuances que indicam aspectos de outro herói mítico inglês que é a história de Robin Hood.

Por sua vez, outra história peculiar que pode ser associada a essa metalinguagem e, por isso, ser selecionada como forma significativa de uma prática multiletrada é a fábula de "Chapeuzinho Vermelho". Esse clássico de origem europeia do século XIV também sofreu releituras, tornando-se, no caso, o filme "Deu a louca na Chapeuzinho". O conto infantil transformou-se em uma paródia, uma releitura bem humorada de tal obra entre tantas outras. Neste filme, contos de fadas bem conhecidos como "João e Maria", "os três porquinhos", "o gigante e o pé de feijão" são ressignificados dentro de uma versão moderna da história da chapeuzinho vermelho. $\mathrm{O}$ filme apresenta vários apectos que se conectam com nossa realidade contemporânea como a tecnologia, a violência, a investigação policial, passíveis de serem analisados e discutidos em sala de aula. As sinopses a seguir transmitem uma ideia do enredo das histórias. 
Figura 2: Sinopses dos filmes
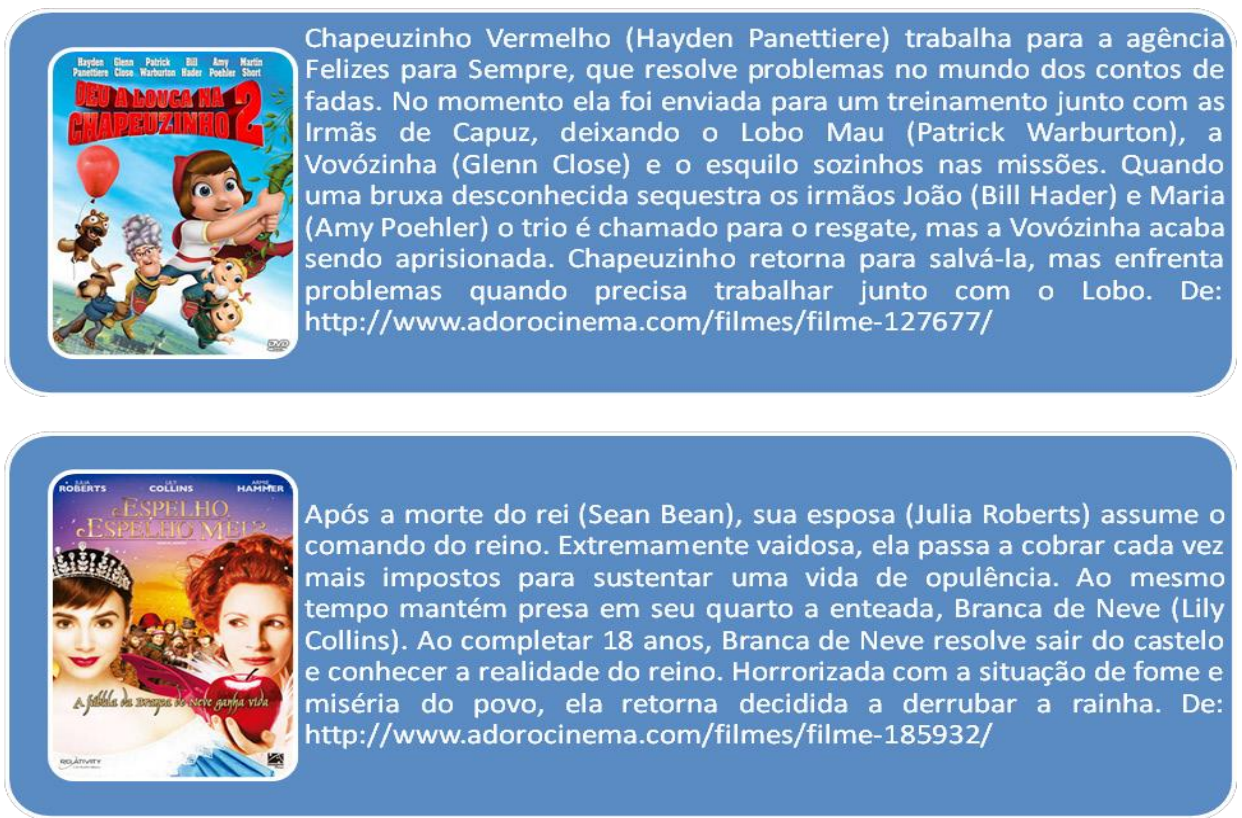

Fonte: Imagens de: http://assistirfilmesonline.biz/deu-a-louca-na-chapeuzinho-2-dublado e http://www.baixarfilmesgratis.org/baixar-filme-espelho-espelho-meu- dublado

No que remete ao como da pedagogia dos multiletramentos, temos como base o fato de o conhecimento humano ser concebido dentro de contextos socioculturais e materiais definidos em ações específicas atreladas a determinadas práticas sociais letradas. Nesse sentido, trazer esta concepção de leitura e escrita para a sala de aula através dos quatro princípios da pedagogia dos multiletramentos, ou seja, a prática situada, a instrução explícita, o enquadramento crítico e a prática transformada, torna-se determinante para qualificar a prática pedagógica.

\subsection{Análise e sugestões sobre os quatro componentes da Pedagogia dos Multiletramentos}

Cope e Kalantziz (2001) alegam a existência de um aspecto epistemológico na pedagogia dos multiletramentos. Para eles, 
nos mundos da vida pública, trabalho e aprendizagem formal, o conhecimento é construído através da imersão na experiência prática (Prática situada); unida com conceitos explícitos e teorias as quais explicam processos subjacentes (Instrução Explícita), através da localização do conhecimento em seu contexto de relevância e reflexão sobre os seus propósitos (Enquadramento Crítico); e através da transferência de conhecimento ganho em um contexto para outro, o qual será inevitavelmente similar e diferente em certos aspectos (Prática Transformada). (COPE e KALANTZIZ, 2001, p. 240)

Considerando a intenção inicial deste artigo, apresentamos alguns pontos da Pedagogia dos Multiletramentos de forma aplicada. Exemplificamos o aspecto da prática situada, da instrução implícita e também do enquadramento crítico através da análise do gênero textual carta aberta. Acreditamos que este gênero, em função de suas características, encaixe-se adequadamente neste tipo de atividade em sala de aula. Ou seja, a partir de determinadas ansiedades, problemas sociais enfrentados por nossos alunos, podemos promover a construção de uma carta aberta à sociedade como forma de manifestação, protesto, ação social e exercício de cidadania.

Para Larsen-Freeman (2000, p. 150), podemos obter orientação, nesse sentido, da abordagem participatória, de Paulo Freire (2011), em que "o objetivo é ajudar os estudantes a entender as forças sociais, históricas, ou culturais que afetam as suas vidas, e então ajudá-los no empoderamento, a tomarem uma ação, tomarem decisões, a fim de terem controle de suas vidas".

A criação e participação na elaboração de uma carta aberta poderá ser feita pela turma como um todo, ou em pequenos grupos, cada grupo abordando diferentes temáticas. Com isso, pretendemos oportunizar práticas de letramento efetivas dentro de uma concepção sociocultural de letramento em sala de aula.

Nesse contexto, concordamos com Bunzen (2010, p. 99) que "discutir os significados do letramento escolar, de um ponto de vista mais sociológico e antropológico, é, de certa maneira, refletir sobre as condições de produção e sobre os modos de circulação de textos (sempre multisemióticos) no cotidiano escolar". Com isso, complementamos que os usos da linguagem e a produção de sentidos são sempre pela instrumentalização semiótica, 
em que os gêneros de texto compõem a produção, circulação e recepção de textos (BUNZEN, 2010).

Retomando o conceito de prática situada, temos que a participação na elaboração de uma carta aberta como forma de exercer cidadania, como ação social é indispensável para alcançarmos em uma prática transformada. Esta produção de sentidos pode também atravessar os muros da escola, produzindo resultados no âmbito social ou não, consituindo-se em uma atividade de imersão ou simulação.

No que diz respeito à Instrução Explícita sobre o processo de elaboração de uma carta aberta, destacamos o quão relevante é proporcionar ao aluno uma oportunidade para o entendimento consciente, analítico e sistemático para a construção de uma carta aberta. Podemos apresentar alguns exemplos de carta aberta para os alunos e trabalharmos nos níveis representacional, social, organizacional. Dessa forma, os significados se referem a que, ou a o que (representacional); como os significados conectam as pessoas que eles envolvem (social); como os significados se vinculam, se organizam na materialidade linguística (organizacional). Analisaremos os recursos disponíveis para construirmos significado neste gênero textual, como será desenvolvido o processo de designing, como os velhos sentidos tornar-se-ão novos (COPE e KALANTZIZ, 2001).

Por sua vez, o Enquadramento Crítico implica a interpretação do contexto cultural e social do sentido já dado, construído, ou no processo de construção de significado. Cervetti, Pardales e Damico (2001) no artigo sobre a comparação entre a leitura crítica e o letramento crítico ressalvam que ambas as abordagens posicionam os leitores como sujeitos ativos no processo de leitura, bem como construtores de significação, enfatizando a relevância de um posicionamento crítico em relação à dialogia estabelecida entre leitor e escritor.

Entretanto, destacamos que para a proposta da pedagogia dos multiletramentos (NLG,1996), a concepção de letramento crítico é a que mais coaduna neste sentido. A história filosófica do letramento crítico possui várias influências, sendo algumas delas a teoria social crítica, o trabalho de Paulo Freire e mais recentemente as concepções pós-estruturalistas que valorizam o discurso, as relações de poder e a dependência do contexto do significado desvinculando a noção de neutralidade, ou verdade nas interpretações e decisões (CERVETTI, PARDALES e DAMICO, 2001). 
letramento mais como uma prática social e política. A linguagem está atrelada à produção de significados que não são neutros e sim ideológicos, evidenciando, em muitos casos, relações explícitas de poder. Há uma relação direta entre comunidade discursiva, uso da linguagem e produção de sentidos culturalmente, socialmente e historicamente embasados. Cervetti, Pardales e Damico (2001) constatam que o letramento crítico assinala as seguintes características:

O letramento crítico envolve um entendimento do modo que as práticas ideológicas e textuais dão forma às representações das realidades nos textos.(...) ajudar os alunos a tornarem-se criticamente letrados tem a ver, em parte, com capacitá-los a detectar e lidar com a dimensão inerentemente ideológica da língua e letramento.(...) eles têm uma oportunidade maior de tomar uma posição mais poderosa com respeito aos textos, rejeitá-los ou reconstruí-los de maneiras que são mais consistentes com suas próprias experiências de mundo. (CERVETTI, PARDALES E DAMICO, 2001, p. 8, tradução nossa)

No caso de uma carta aberta, sugerimos analisar criticamente como tal carta se encaixa nos significados locais e significados mais globais. As seguintes perguntas, sugeridas por Cope e Kalantziz (2001, p. 247) e por Cervetti, Pardales e Damico, (2001) certamente auxiliarão os professores nesta tarefa. É importante destacar que esta Tabela 2 não explora em completo as questões de gênero textual conforme a teoria bakhtiniana.

Tabela 2: Perguntas para o letramento crítico

\begin{tabular}{|l|l|}
\hline 1) Qual é a função imediata & $\begin{array}{l}\text { O que ela produz? Para quem } \\
\text { ela é produzida? Por quem é } \\
\text { elaborada?Em conformidade com }\end{array}$ \\
& $\begin{array}{l}\text { quem? Por quê? Como os significa- } \\
\text { dos apresentados na carta são rela- } \\
\text { cionados a certas figuras sociais ou } \\
\text { eventos sociais? Qual o propósito } \\
\text { do texto? }\end{array}$ \\
\hline
\end{tabular}




\begin{tabular}{|l|l|}
\hline $\begin{array}{l}\text { 2) Qual é o contexto social e } \\
\text { cultural maior desta carta? }\end{array}$ & $\begin{array}{l}\text { Envolve a análise de questões como } \\
\text { cultura, história, sociedade, política } \\
\text { e valores? Que visão de mundo a } \\
\text { carta suscita? Quais não? } \\
\text { Quais são outras construções de } \\
\text { mundo possíveis? }\end{array}$ \\
\hline $\begin{array}{l}\text { 3) Qual a estrutura e o contex- } \\
\text { to imediato da carta aberta? }\end{array}$ & $\begin{array}{l}\text { Situações, conexões, os sistemas, } \\
\text { os relacionamentos, os efeitos pro- } \\
\text { duzidos, relacionados com ela. } \\
\text { Como a carta tenta chamar a aten- } \\
\text { ção dos leitores para aceitarem as } \\
\text { suas ideias? Quem vai se favorecer } \\
\text { deste texto e quem não? }\end{array}$ \\
\hline
\end{tabular}

\subsubsection{A Análise Crítica do Discurso e o Enquadramento Crítico}

Considerando que a linguagem é elemento essencial dos processos sociais materiais, a Análise Crítica do Discurso (ACD), formulada por Fairclough (2001), torna-se instrumento adequado para a análise das práticas sociais implicadas pela pedagogia dos multiletramentos. Mais especificamente, torna-se referencial teórico relevante para compor o enquadramento crítico veiculado nesta pedagogia. Professores podem ser auxiliados em suas escolhas temáticas, no modo como direcionar os questionamentos, as discussões, os letramentos críticos e a leitura crítica em sala de aula, considerando o suporte teórico da ACD.

Além disso, os professores ao desconstruírem, analisarem criticamente com os alunos as práticas sociais semióticas possibilitarão que eles desenvolvam um letramento crítico da realidade, e práticas sociais evidenciadas na contemporaneidade. Motta Roth, ao destacar a importância da leitura crítica em sala de aula, salienta que:

a pedagogia crítica se caracteriza por pressupor que o professor tem um poder transformador (Johnston, 1999) e por estabelecer a conexão entre a prática pedagógica e as questões mais amplas que circulam numa determinada época em um dado grupo social. (MOTTA-ROTH, 2007, p. 244)

Nesse paradigma, ler criticamente é importante, pois leva o aluno a pensar sobre sua própria condição humana, sua história, sua cultura, seus 
práticas e o papel relevante que a linguagem estabelece nestas mesmas práticas, entre outros aspectos (MOTTA-ROTH, 2007).

Com isso, o conceito de semiose faz-se relevante para entendermos melhor as práticas sociais contemporâneas e como interpretá-las criticamente. Para Fairclough (2001, p. 122), a ACD é consolidada "em uma visão de semiose como uma parte irredutível dos processos sociais materiais. A semiose inclui todas as formas de produção de sentidoimagens, linguagem corporal, bem como a língua".

O conceito de semiose tem relação direta com a pedagogia dos multiletramentos. Conforme Fairclough (2001), toda prática social possui um elemento semiótico. Todas as práticas elaboram suas formas específicas de produzirem sentidos que precisam ser lidos, interpretados e concebidos criticamente.

Fairclough (2001) explica que a semiose pode ser vista a partir de três modos que serão detalhados a seguir. Primeiramente, como parte de uma dada atividade social, em que a linguagem é usada de acordo com este contexto. Temos então a associação da língua com a situação de uso particular que veicula.

Segundo, a semiose é concebida através das representações determinadas na prática social em questão. Para esse modo, Fairclough (2001, p. 123) destaca que "os atores sociais dentro de qualquer prática produzem representações de outras práticas, bem como representações de suas próprias práticas", então tais representações são também relevantes para se entender o uso semiótico da linguagem nos mais variados contextos. Há uma recontextualização de sentidos já dados em novas práticas.

O terceiro modo da semiose envolve as identidades dos sujeitos e seu desempenho, as posições particulares dentro das práticas sociais. As identidades são diferentemente expostas e desempenhadas de acordo com dada participação em comunidades de discurso. Os estilos são ressaltados também como parte de práticas semióticas, evidenciando modos definidos socialmente, culturalmente de ser.

Com isso, Fairclough (2001) também elucida a análise dos gêneros como parte das práticas sociais e elementos fundamentais na constituição dos multiletramentos. As representações e autorrepresentações das práticas sociais vão se constituir em discursos que precisam ser desvelados e, em muitos casos, simulados, praticados, transformados a partir do trabalho de análise crítica realizado em aula.

Sendo assim, a Análise Crítica do Discurso, que aqui foi 
sumariamente apresentada, pode contribuir como metodologia de análise das práticas sociais sustentadas pelo uso semiótico da linguagem, constituindo discursos, gêneros que precisam ser avaliados no contexto de sala de aula. A pedagogia dos multiletramentos, por sua vez, pode beneficiar com este instrumento, na análise da atual realidade social, buscando desvelar valores, ideologias.

Como parte final neste processo do como da pedagogia do NLG, evidenciamos a prática transformada que consiste na aplicação criativa do que se seleciona e aprende, produzindo novos conhecimentos. Para Rojo (2012, p. 30), todos os três componentes da Pedagogia visam "como instância última, à produção de uma prática transformada, seja de recepção ou de produção/distribuição (redesign)" Neste caso, isso ocorre ao elaborarmos uma carta e divulgá-la na escola, por exemplo. Por outro lado, a prática situada também remete à possibilidade de o aluno, após participação neste processo de uso, projeto de imersão, leitura e escritura de texto, conseguir usar parte deste conhecimento para elaborar outros gêneros textuais, em contextos variados.

No caso, o trabalho com a carta pode auxiliá-lo na construção de outros documentos, solicitações em contextos diferentes no mundo real. Ele será capaz de destacar seus interesses particulares ou dos outros. Esperamos que o aluno faça relações e consiga transferir esses conhecimentos, a fim de produzir transformação pessoal, ou coletiva. Acreditamos que para isso, exige-se do sujeito um comprometimento, um respeito maior com suas práticas sociais, a fim de produzir mudanças significativas para a coletividade por meio de uma ética social.

Quanto aos filmes analisados, eles também podem ser analisados dentro do pensamento do letramento crítico e o como se trabalhar com eles será embasado na pedagogia dos multiletramentos. Os alunos podem produzir vídeos, simular a produção de textos midiáticos, veiculando questões de ética social, cultura, história e valores a partir das ideias extraídas dos filmes como forma de transformar os seus valores, o da comunidade escolar, se divulgado na escola, e valores da comunidade.

Dionísio (2007), ao discutir sobre os estudos atuais a respeito das práticas de leitura e escrita em um contexto sociocultural, histórico e ideológico, aponta certos caminhos. Ela sugere que se oportunize aos estudantes experiências em práticas sociais e culturais variadas, com 
suas linguagens especializadas, no intuito de capacitar o sujeito ao empoderamento e à capacidade de se transformar, bem como transformar estes contextos. Para a autora, trata-se de

\begin{abstract}
Um envolvimento em 'práticas situadas', que se entendem como práticas significativas dentro de diversas 'comunidades de prática' (WENGER, 1998) e onde os sujeitos podem desempenhar múltiplos e diferenciados papéis, baseados nas suas experiências e conhecimentos prévios. A este nível é dado particular destaque ao uso de textos que se podem caracterizar como multimodais e a variadas tecnologias e suportes do escrito específicas das atuais paisagens semióticas. Deste modo, a produção e o 'consumo' do conhecimento estão sempre interligados, não havendo fronteiras entre eles. Quer isto dizer que os jovens não são apenas consumidores de conhecimento, mas agentes activos na sua produção. (DIONÍSIO, 2007, p. 3).
\end{abstract}

Esse ponto de vista de Dionísio (2007) ostenta muito do que se pretende atingir pelo uso da pedagogia dos multiletramentos em sala de aula. Como afirmado no início do artigo, a intenção é fazer com que professores em formação continuada possam complementar suas práticas, inserindo mais frequentemente outras práticas de letramento, além das escolares, para serem discutidas, analisadas, simuladas e transformadas no ambiente da escola.

\title{
30 Processo de Formação Continuada de Professores de Línguas
}

Destacamos aqui a relevância do processo de formação continuada como forma de reflexão e ação no contexto imediato de ensino, a fim de propor melhoramentos na prática docente, bem como reformulações de crenças que porventura impossibilitem um desenvolvimento adequado das atividades em sala de aula. De acordo com Richter (2011, p. 109), os professores "têm crenças e trabalhar pela formação de professores significa contribuir para a reelaboração dessas crenças". Com isso, no âmbito da formação continuada também devemos refletir sobre as nossas crenças e tentarmos modificá-las, caso necessário.

Richter (2011, p. 111) aponta que "um conceito será classificado como crença ("achismo") na medida em que for aceito como verdade sem as devidas evidências embasadoras capazes de fazê-lo resistir a futuros 
questionamentos". O que buscamos então é transformar nossas crenças em conhecimentos significativos, envolver-nos em pesquisa e propormos melhoramentos em nossas práticas associando a teoria com nossas experiências cotidianas.

Rojo (2012) ao discorrer sobre os multiletramentos, a diversidade cultural e as linguagens na escola, aponta que muitos professores estão abertos a introduzir mais frequentemente as TICs em sala de aula, porém existe certa inquietação neste sentido. Rojo (2012) revela sua visão, com apoio na pedagogia dos multiletramentos:

Sinto uma grande adesão dos docentes aos princípios que subjazem a esse tipo de concepção de educação. Nossos desafios não estão no embate com a reação, mas em como implementar uma proposta assim: a) o que fazer quanto à formação/remuneração/avaliação de professores; b) o que mudar (ou não) nos currículos e referenciais, na organização do tempo, do espaço e da divisão disciplinar escolar, na seriação, nas expectativas de aprendizagem ou descritores de 'desempenho', nos materiais e equipamentos disponíveis nas escolas e salas de aula. Mas esses gigantescos desafios parecem bem pequenos se de fato tivermos a adesão dos professores e alunos a essas ideias. (grifo nosso) (ROJO, 2012, p. 31)

Fica claro, na citação de Rojo, sobre a Pedagogia dos Multiletramentos que se deve pensar, refletir, hipotetizar, testar e agir muito para implementar as práticas docentes em sala de aula. O sistema educacional e seus gestores devem incentivar e apoiar os professores na participação de pesquisas, e aprimoramento profissional. Por sua vez, os professores têm de estar abertos e desejosos por mudança e o principal, a fim de trabalhar significativamente para dar um novo rumo, ou proporcionar melhoramentos em suas práticas.

O processo de formação continuada então necessita, conforme Ghedin (2005), "criar e recriar formas e modelos, bem como espaços e tempos para reflexão, é ainda uma busca, um horizonte que precisamos atingir, mas é nisto que repousa a possibilidade de instauração de um processo de autonomia e liberdade".

Os professores precisam ter um senso de responsabilidade ética, como enfoca Freire (2011), na prática e no nosso atuar docente. Para Freire 
(2011, p. 24), “a reflexão crítica sobre a prática se torna uma exigência da relação Teoria/Prática sem a qual a teoria pode ir virando blá-blá-blá e a prática, ativismo."

Neste sentido, é de extrema importância que o professor busque sempre o aperfeiçoamento, fazendo uma análise crítica dos saberes culturais associados ao exercício de sua profissão. A pedagogia dos multiletramentos certamente contribui neste sentido, por envolver o aperfeiçoamento dos saberes pedagógico-didáticos do professor em consonância com as realidades e linguagens semióticas características de seu tempo.

Ghedin (2005), em seu artigo sobre a reflexão das práticas de docência no processo de formação continuada, salienta sete aspectos interessantes, nos quais podem ser analisados criticamente neste caminho, para o aprimoramento profissional do professor. O referido autor (2005, p. 26) cita "a construção da identidade profissional do professor; os saberes da docência; os saberes pedagógicos; uma proposta; a escola como lugar de aprendizagem e trabalho do professor; a participação do professor na organização e gestão da escola; enfrentando as mudanças". Observamos que muito mais aprofundamento e discussões sobre o assunto são necessários, se quisermos contemplar esses sete aspectos satisfatoriamente nas escolas.

Tais questões abrangem o complexo da formação continuada, porém de nosso interesse maior são os saberes condizentes com a pedagogia e didática integradas, o processo de ação e reflexão da prática, os quais são essenciais para o desenvolvimento da atuação docente.

De forma geral, os professores precisam estar sempre repensando e reconstruindo as maneiras já convencionadas de se aprender o conhecimento, a linguagem e suas manifestações. O questionamento, a curiosidade, a pesquisa tornam-se fundamentais neste contexto. Ghedin (2005, p. 29) elucida que "a pesquisa, como princípio orientador, exige que o profissional de educação seja um professor sujeito do conhecimento. $\mathrm{O}$ professor deixa de ser o protagonista dogmático de um processo de transmissão de conhecimentos, e assume seu trabalho como partícipe da construção conjunta." Isto é destacado pelo que Freire (2011, p.30) menciona: "não há ensino sem pesquisa e pesquisa sem ensino".

Guimarães (2005, p. 33) alega que "é consensual que a formação inicial e continuada do professor deve se constituir num processo contínuo e interligado". Com isso, fica claro a necessidade de constante atualização dos professores. Em contextos que isso porventura possa não ocorrer, 
a formação continuada pode ser instigada, incentivada no âmbito da formação inicial e constantemente estimulada e valorizada dentro da escola por seus gestores. A formação continuada está implicada em toda atuação do homem, principalmente, ao considerar as constantes transformações em nossa realidade.

\section{Considerações finais}

Considerando o objetivo proposto no artigo, percebemos a necessidade de maiores estudos e pesquisas sobre o assunto. De fato, podemos perceber a relevância da Pedagogia dos Multiletramentos associada à Análise do Discurso para a sala de aula de leitura e escrita em língua materna e/ou estrangeira. A análise apresentada anteriormente se constitui em uma maneira de repensar a Pedagogia dos Multiletramentos de maneira mais prática. Certamente, no contexto de sala de aula, ao se aplicar as atividades, é que teremos mais dados sobre a questão. No momento, cabe aos professores buscar um maior entendimento sobre a Pedagogia dos Multiletramentos, fazendo experimentações, criando hipóteses, adaptando, reformulando atividades e avaliando esta didática para o ensinar. Desse modo, a pesquisa-ação do professor pode se configurar em um processo efetivo de formação continuada.

\section{Referências}

BRANCA DE NEVE. In: Wikipédia. A enciclopédia livre. Disponível em: <. http://pt.wikipedia.org/wiki/Branca_de_Neve>. Acesso em: 29/09/12

BUNZEN, C. Os significados do letramento escolar como uma prática sociocultural. In: VÓVIO, Cláudia; SITO, Luanda; DE GRANDE, Paula. Letramentos: rupturas, deslocamentos e repercussões de pesquisas em Linguística Aplicada. Campinas, SP: Mercado de Letras, 2010. p. 99-120.

BURNS, A. Collaborative Action Research for English Language Teachers. Cambridge University Press, 1999.

CERVETTI, G.; PARDALES, M. J.; DAMICO, J. S. A tale of differences: comparing the traditions, perspectives, and educational goals of critical reading and critical literacy. Reading Online, v. 4, n. 9, 2001. Disponível em: http://www.readingonline.org/articles/art_index.asp?HREF=/articles/ cervetti/index.html>. Acesso em: 15 ago. 2012. 
CHAPEUZINHO VERMELHO. In: Wikipédia. A enciclopédia livre. Disponível em:

http://pt.wikipedia.org/wiki/Chapeuzinho_Vermelho> Acesso em: 29/09/12

DIONÍSIO, M. L. Literacias em contexto de intervenção pedagógica: um exemplo sustentado nos Novos Estudos de Literacia. Revista Educação

- UFSM, v. 31, n.1, 2007. Disponível em: http://coralx.ufsm.br/revce/ revce/2007/01/a6.htm. Acesso em 26 junho 2012

FAIRCLOUGH, N. Critical discourse analysis as method in scientific research. In: WODAK, R. Methods of critical discourse analysis. London: SAGE, 2001.p. 121-138.

FAIRCLOUGH, N. Analysing discourse: textual analysis for social research. London/New York: Routledge, 2003

FREIRE, P. Pedagogia da Autonomia-saberes necessários à prática educativa. Editora Paz e Terra, São Paulo, 2011.

GIMENEZ, T. N. Learners Becoming Teachers: an exploratory study of beliefs held by prospective and practicing EFL teachers in Brazil. 1994. Tese de Doutorado- Universidade de Lancaster,1999.

GHEDIN, E. A reflexão sobre a prática cotidiana-caminho para a formação contínua e para o fortalecimento da escola enquanto espaço coletivo. Boletim 13- Formação Contínua de Professores, 2005. Disponível em: http://www.tvbrasil.org.br/fotos/salto/series/150934FormacaoCProf.pd f. Acesso em: 24 set 2012.

GUIMARÃES, V. S. Os saberes dos professores-ponto de partida para a formação contínua. Boletim 13- Formação Contínua de Professores, 2005.2 Disponível em: http://www.tvbrasil.org.br/fotos/salto/ series/150934FormacaoCProf.pdf. Acesso em: 24 set 2012.

HALLIDAY, M. Language as social semiotic- the social interpretation of language and meaning. Open University Set Book, 1978. 
JEWITT, C. Multimodality and literacy in school classrooms. Review of Research in Education, v. 32, n. 1, p. 241-267, 2008. Disponível em: <http://rre.sagepub.com/content/32/1/241.full.pdf+html>. Acesso em: 15 ago. 2012.

KALANTZIS, M.; COPE, B. A multiliteracies pedagogy: a pedagogical supplement. In: COPE, B.; KALANTZIS, M. (Eds.). Multiliteracies: literacy learning and the design of social futures. London/New York: Routledge, 2000. p. 239-248.

KRESS, G. e LEEUWEN, T. Reading images. Routledge, London and New York, 1996.

LARSEN-FREEMAN, D. Techniques and Principles in Language Teaching. Oxford University Press, 2000.

MOTTA-ROTH, D. . Para ligar a teoria à prática: roteiro de perguntas para orientar a leitura/análise crítica de gêneros. In: MOTTA-ROTH, D.; CABAÑAS, T.; HENDGES, G. (Org.). Análises de textos e de discursos: relações entre teorias e práticas. $1^{a}$ ed Santa Maria: PPGL Editores, 2008, v. 1, p. 243-272.

RICHTER, M. G. Profissionalização docente segundo a teoria holística da atividade: estudo empregando software de mapeamento semântico. In: ALBUQUERQUE, R.;Motta, V. A. (Org.). Linguagem e interação: O ensino em pauta.São Carlos: Pedro \& João, 2011. p.109-140.

ROBIN HOOD. In: Wikipédia. A enciclopédia livre. Disponível em: <. http://pt.wikipedia.org/wiki/Robin_Hood >Acesso em: 29/09/12

ROJO, R e MOURA, E. Multiletramentos na escola. São Paulo: Parábola Editorial, 2012.

STREET, B. V. What's new in New Literacy Studies? Critical approaches to literacy in theory and practice. Current Issues in comparative Education, v. 5, n. 2, p. 77-91, 2003. Disponível em: <http://www.tc.columbia.edu/ cice/Issues/05.02/52street.pdf $>$. Acesso em: 16 jul. 2012. 
THE NEW LONDON GROUP. A Pedagogy of Multiliteracies: designing social futures. Harvard Educational Review, v. 66, n. 1, p. 60-92, 1996. Disponível em: http://vassarliteracy.pbworks.com/f/ Pedagogy+of+Multiliteracies_New+London+Group.pdf>. Acesso em: 09 jun. 2012.

Recebido em: outubro de 2012. Aprovado em: abril de 2013. 